\title{
Effects of Gamma Irradiation on Shoot, Root and Survival Percent in Strawberry cv. Chandler under In vitro Conditions
}

\author{
Rucku Gupta*, V.K. Wali, Parshant Bakshi, Guruupkar Singh, \\ Rafiq Ahmad Shah and Sohnika Rani
}

\section{Division of Fruit Science, Sher-e-Kashmir University of Agricultural Sciences \& Technology of Jammu, Faculty of Agriculture, Main Campus, Chatha, Jammu-180009, India}

*Corresponding author

K e y w o r d s
Gamma irradiation,
Strawberry, in vitro
Article Info
Accepted:
$\begin{aligned} & 10 \text { February } 2018 \\ & \text { Available Online: } \\ & 10 \text { March } 2018\end{aligned}$

\section{A B S T R A C T}

The effects of different doses $(0,10,30,50$ and $60 \mathrm{~Gy})$ of radioactive cobalt $\left({ }^{60} \mathrm{Co}\right)$ rays on axillary buds of strawberry were investigated under in vitro conditions. The results showed that irradiated buds had increased shoot proliferation percentage, average number of shoots, shoot length, average number of roots, root length, root initiation percentage, survival percentage and number of leaves. However, at higher doses it showed inhibitory effects and significant decreases in all above parameters was observed. The highest shoot proliferation per cent $(91.06 \%)$, average number of shoots (8.44) and shoot length (2.77 $\mathrm{cm}$ ) was recorded when buds were irradiated with $10 \mathrm{~Gy}$ gamma dose followed by $30 \mathrm{~Gy}$ gamma dose. Gamma doses over 30 Gy resulted in sharp decreases in all parameters examined. The highest root initiation percentage $(91.06 \%)$, average number of roots (5.58) and root lengths $(3.62 \mathrm{~cm}$ ) was recorded from $10 \mathrm{~Gy}$ gamma rays. After 7 weeks of hardening maximum survival per cent $(86.66 \%)$ was recorded in un-irradiated (control) buds followed by buds irradiated with $10 \mathrm{~Gy}$ dose whereas, maximum number of leaves were recorded in case of cultures irradiated with $10 \mathrm{~Gy}$. Thus it can be concluded that lower doses of gamma rays can improve the survival and growth of explants under in vitro conditions.

\section{Introduction}

The genus Fragaria, from the family Rosaceae is a dicotyledonus, perennial herb grown in most arable regions of the world. The cultivated strawberry has evolved as natural hybrid between the F.virginiana Duch and $F$. chiloensis (L) Duch. There are about 20 recognized species of strawberries in five chromosomes groups $(x=7)$ : ten diploids, four tetrapolids, one pentaploid, one hexaploid and four octoploids. The cultivated strawberry is an octoploid $(2 n=8 x=56)$. In recent past, strawberry has drawn attention of scientists for its genetic improvement.

Plant tissue culture tools have been used for increasing the speed and efficiency of the breeding process, to improve the accessibility of the existing germplasm and to create new 
variations for crop improvement through micro-propagation, anther culture, in vitro selection (Karim et al., 2015).

Induction of mutations using in vitro cultures and micropropagation of desirable mutants offers an alternative choice to broaden the spectrum of genetic variation among vegetatively propagated plants such as strawberry. Induced mutations with gamma irradiation and chemical mutagenesis provides an excellent tool for the rapid creation and increase in the variability in crop species and thus have contributed significantly to plant improvement. Gamma rays as an ionizing radiation affect plant growth and development by inducing cytological, biochemical, physiological and morphological changes in cells and tissues via producing free radicals in cells (Gunckel and Sparrow, 1961; Kim et al., 2004; Wi et al., 2005). The higher doses of gamma radiation had been found be inhibitory (Radhadevi and Nayar, 1996; Kumari and Singh, 1996), whereas, lower doses may be stimulatory. Low doses of gamma rays have been reported to increase cell proliferation, germination, cell growth, enzyme activity, stress resistance, and crop yields (Charbaji and Nabulsi, 1999; Baek et al., 2005; Chakravarty and Sen, 2001; Kim et al., 2000, 2005). Therefore, this study was aimed to determine the optimum dose of gamma rays for improving shoot, root and survival per cent of strawberry under in vitro conditions.

\section{Materials and Methods}

The present study was conducted at Tissue Culture Laboratory, Division of Fruit Science, Sher-e-Kashmir University of Agricultural Sciences \& Technology of Jammu, Jammu during the year 2015- 2016. The axillary buds of strawberry plants were used as the starting material for in vitro grown cultures. Axillary bud cultures ( 25 buds/ culture bottle) were used as replicates for each treatment. Before irradiated the cultures, the axillary buds were washed thoroughly in running tap water for 20 minutes to remove the surface contaminants and was then treated with Tween 20 (2-3 drops $/ 100 \mathrm{ml}$ of $\mathrm{H}_{2} \mathrm{O}$ ) for 4-5 minutes and washed thoroughly with distilled water. After that, the washed buds were treated with $(0.5 \%)$ bavistin for 6-7 minutes and then washed 3-4 times with distilled water. Finally, sterilization procedures were carried out under aspectic conditions in a laminar- air flow cabinet. The axillary buds were subjected to surface sterilization using mercuric chloride $(0.1 \%)$ for 4 minutes. The axillary buds were then cultured on MS media supplemented with BAP $(1.00 \mathrm{mg} / \mathrm{l})$ in combination with $\mathrm{GA}_{3}$ $(1.00 \mathrm{mg} / \mathrm{l})$ which was already standardized before irradiating the explants with different dosage of gamma rays and same media composition was used for shoot proliferation also.

In vitro mutagenesis was carried out by irradiating the cultures with different doses of gamma rays in gamma chamber at Punjab Agriculture University, Ludhiana. The gamma ray treatment was performed using blood Irradiator $\left({ }^{60} \mathrm{Co}\right.$ source, Dose 11 Gy per minute). The axillary buds were irradiated with four doses of gamma rays viz., 10, 30, 50, 60 Gy for induction of mutations. The Gamma ray irradiated axillary buds were cultured on growing media for shoot proliferation and were then transferred to rooting medium (MS medium supplemented with IBA $1.5 \mathrm{mg} / \mathrm{l}$ and activated charcoal $200 \mathrm{mg} / \mathrm{l}$ ). The miniature explants were hardened and grown in glasshouse in pots containing soil: FYM (1:1 $\mathrm{v} / \mathrm{v})$ for 7 weeks. The effect of gamma irradiation on the proliferation percentage, average number of shoots, shoot length after 8 weeks of culturing, root initiation percentage, average number of roots, root length after 6 weeks of culturing and the per cent survival and number of leaves after 7 weeks of transferring were recorded as per the 
standardized methods. The data were analysed according to completely Randomized Block design (CRD) as described by Panse and Sukhatme (2000).

\section{Results and Discussion}

The in vitro mutagenesis was carried out by irradiating the cultures with the gamma rays at four doses viz., 10, 30, 50 and $60 \mathrm{~Gy}$. The staring material used was axillary buds. None of the doses were found to be lethal as axillary buds grew normally after irradiation. The effects of gamma doses on shoot proliferation percentage after 4 weeks of incubation, average number of shoots and shoot length after 6 weeks of culturing are shown in Table 1 and depicted in Figure 1.

Stimulatory effect of low doses of gamma irradiation on all parameters was observed in case of cultures irradiated with $10 \mathrm{~Gy}$ and cultures irradiated with $30 \mathrm{~Gy}$. However, the inhibitory effect of gamma radiation on shoot proliferation percentage, average number of shoots and shoot length was observed in the doses over 30 Gy. The highest shoot proliferation per cent, maximum average number of shoots and shoot length was 91.06 $\%, 8.22 \mathrm{~cm}$ and $2.77 \mathrm{~cm}$ respectively from the 10 Gy gamma treatments.

The results obtained in the present investigation are similar to those of Charbaji and Nabulsi (1999) in grapevine (Vitis vinifera L). They observed that lower doses of gamma rays $(5,7 \mathrm{~Gy})$ stimulated the growth of the shoot tip and single node explants. In the present studies, the positive response of strawberry to low dose (5 Gy) of gamma irradiation agrees with the hypothesis proposed by Fowler and McQueen (1972), that the stimulatory effects of low doses of irradiation result in increased seedling vigour. Stimulation of growth with lower doses of gamma rays has been reported in various crops, such as Rudbeckia laciniata (Shukla et al., 1986), Gerbera Jamesonii (Laneri et al., 1990). Enhancement in multiplication ratio at low doses (15 Gy) of Musa species have also been reported by Kulkarni et al., (1997). Similar trend has also been reported by Mishra et al., (2007). Cambecedes et al., (1992) also reported the decrease in ability to produce shoots on increasing the radiation dose in Lonicera species. Jain (1997) reported the inhibitory effects of higher doses of gamma rays on strawberry cultures. He found that most dead number of shoots and $<1 \mathrm{~cm}$ long was highest in shoot cultures developed from $15 \mathrm{KR}$ irradiated axillary buds. They also reported that the number of roots per shoot decreased at higher gamma dosage (10 KR and $15 \mathrm{KR})$. The increased plant vigour caused by irradiation could be explained by stimulation of biosynthesis of some amino acids like Iysine and phenylalanine (Antonov et al., 1989); modification of some enzymes activity e.g. Polyphenol oxidase, catalases and peroxidases which are great in the leaf of treated plants (Lage and Esquibel, 1997; Ghiorghita et al., 1985; Freidman, 1985, Grossman and Craig, 1982) for increase of primary biochemical processes, uptake of mineral nutrients (Al-Oudat, 1990) and photosynthesis (Antonov, 1985).

The per cent root initiation was also influenced by gamma irradiation. The data recorded on per cent root initiation at 14 days interval i.e. after 14, 21 and 28 days after the subculture is given in Table 2. Among the different gamma irradiation doses, percent root initiation after 28 days of sub-culturing was $91.06 \%$ in plantlets arising from $10 \mathrm{~Gy}$, that is more than control $(86.63 \%)$ while plantlets arising from 60 Gy showed only $46.44 \%$ root initiation. The data related to the effect of irradiation on the roots parameters are presented in Table 3. It was observed that average number of roots and root length has grown faster as shown in Figure 2. 
Table.1 Effect of different doses of gamma rays on shoot proliferation per cent, average number of shoots and shoot length of strawberry cv. Chandler

\begin{tabular}{|c|c|c|c|}
\hline Treatment & $\begin{array}{c}\text { Shooting } \\
\text { Proliferation }(\%)\end{array}$ & Average no. of shoot & $\begin{array}{c}\text { Average shoot length } \\
(\mathbf{c m})\end{array}$ \\
\hline $\mathbf{0 ~ G y}$ & $82.20(65.10)$ & 6.51 & 2.22 \\
\hline $\mathbf{1 0} \mathrm{Gy}$ & $91.06(72.81)$ & 8.44 & 2.77 \\
\hline $\mathbf{3 0} \mathrm{Gy}$ & $86.66(68.98)$ & 7.22 & 2.55 \\
\hline $\mathbf{5 0} \mathrm{Gy}$ & $55.55(48.17)$ & 5.23 & 1.66 \\
\hline $\mathbf{6 0} \mathrm{Gy}$ & $46.66(43.17)$ & 4.62 & 1.44 \\
\hline $\mathbf{C D}$ & 7.35 & 0.40 & 0.25 \\
\hline
\end{tabular}

Table.2 Effect of different doses of gamma rays on root initiation of strawberry cv. Chandler

\begin{tabular}{|c|c|c|c|c|}
\hline Treatment & Root initia & $\operatorname{cent}(\%)$ & & \\
\hline & 14 days & 21 days & 28 days & Mean \\
\hline $0 \mathrm{~Gy}$ & 53.30 & 64.40 & 86.63 & 68.11 \\
\hline $10 \mathrm{~Gy}$ & 57.76 & 66.63 & 91.06 & 71.82 \\
\hline $30 \mathrm{~Gy}$ & 51.06 & 55.53 & 73.30 & 59.96 \\
\hline $50 \mathrm{~Gy}$ & 39.96 & 53.30 & 64.40 & 52.55 \\
\hline $60 \mathrm{~Gy}$ & 28.83 & 35.53 & 46.63 & 37.00 \\
\hline Mean & 46.18 & 55.08 & 72.40 & \\
\hline CD (0.05) & tment & $\begin{array}{l}\text { ber of } \\
\text { f days }\end{array}$ & & \\
\hline
\end{tabular}

Table.3 Effect of different doses of gamma rays on the average root number and root length of strawberry cv. Chandler

\begin{tabular}{|c|}
\hline Treatment \\
\hline $0 \mathrm{~Gy}$ \\
\hline $10 \mathrm{~Gy}$ \\
\hline $30 \mathrm{~Gy}$ \\
\hline $50 \mathrm{~Gy}$ \\
\hline $60 \mathrm{~Gy}$ \\
\hline $\mathrm{CD}$ \\
\hline
\end{tabular}

\begin{tabular}{|c|c|}
\hline Average no. of root & A verage root length (cm) \\
\hline 5.25 & 3.32 \\
\hline 5.58 & 3.62 \\
\hline 3.54 & 2.47 \\
\hline 2.81 & 2.14 \\
\hline 1.84 & 1.96 \\
\hline 0.39 & 0.36 \\
\hline
\end{tabular}

Table.4 Percent survival of irradiated strawberry plantlets of cv. chandler in glasshouse

\begin{tabular}{|c|}
\hline Treatment \\
\hline 0 Gy \\
\hline 10 Gy \\
\hline 30 Gy \\
\hline 50 Gy \\
\hline 60 Gy \\
\hline CD \\
\hline
\end{tabular}

\begin{tabular}{|c|c|}
\hline Survival percentage & No. of leaves \\
\hline $86.66(68.98)$ & 4.40 \\
\hline $75.55(60.90)$ & 5.68 \\
\hline $68.88(56.28)$ & 3.66 \\
\hline $55.55(48.17)$ & 2.84 \\
\hline $46.66(43.05)$ & 2.62 \\
\hline 11.03 & 0.8 \\
\hline
\end{tabular}


After 4 weeks of incubation

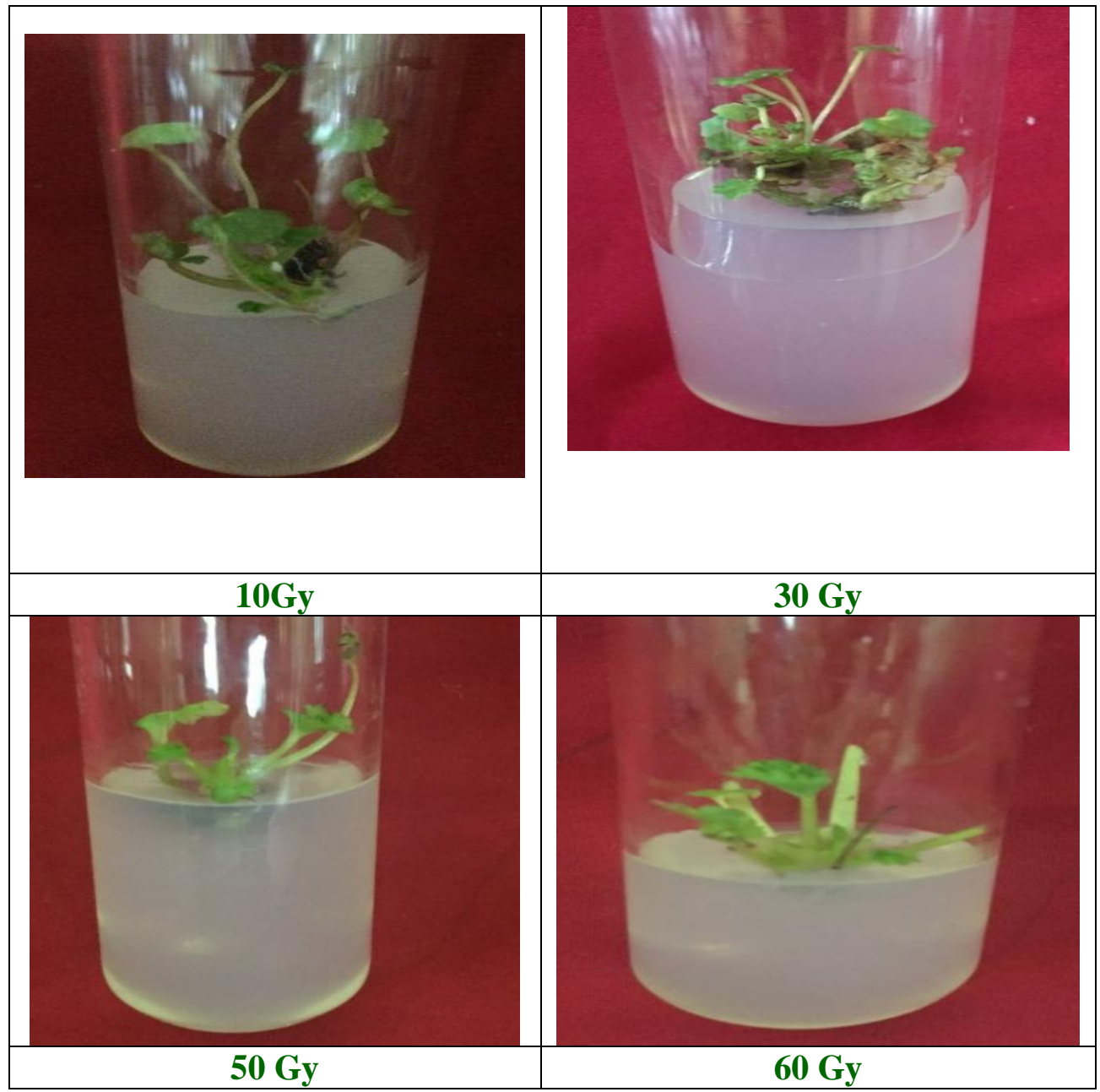

After 6 weeks of culturing

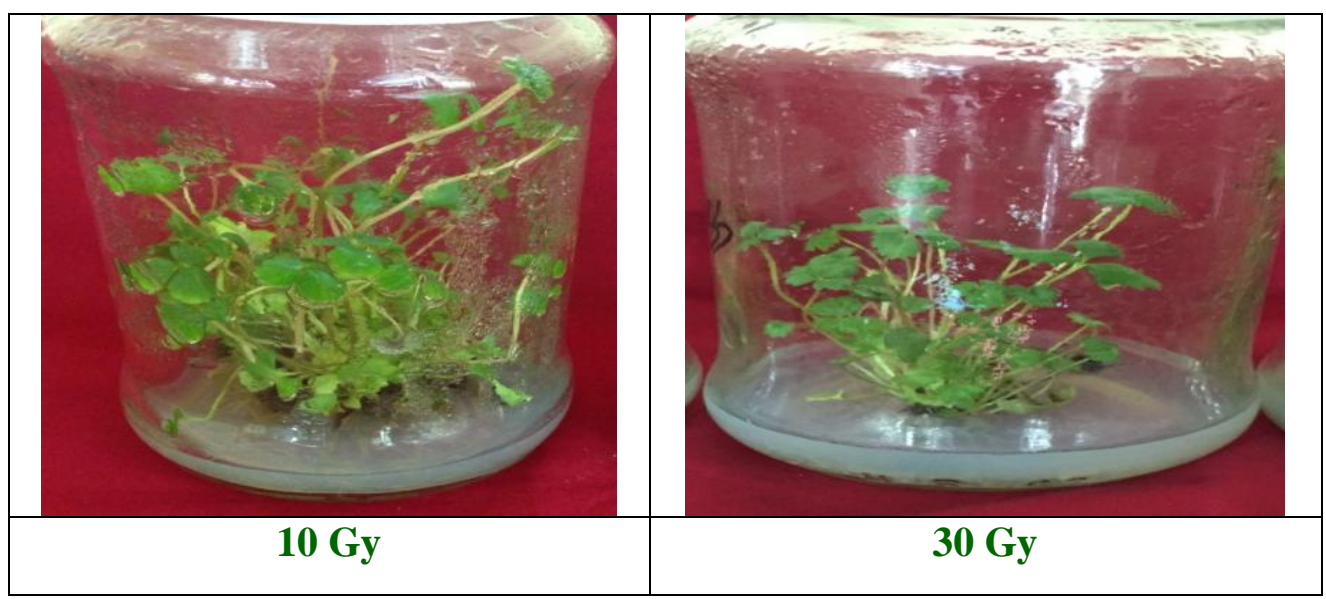




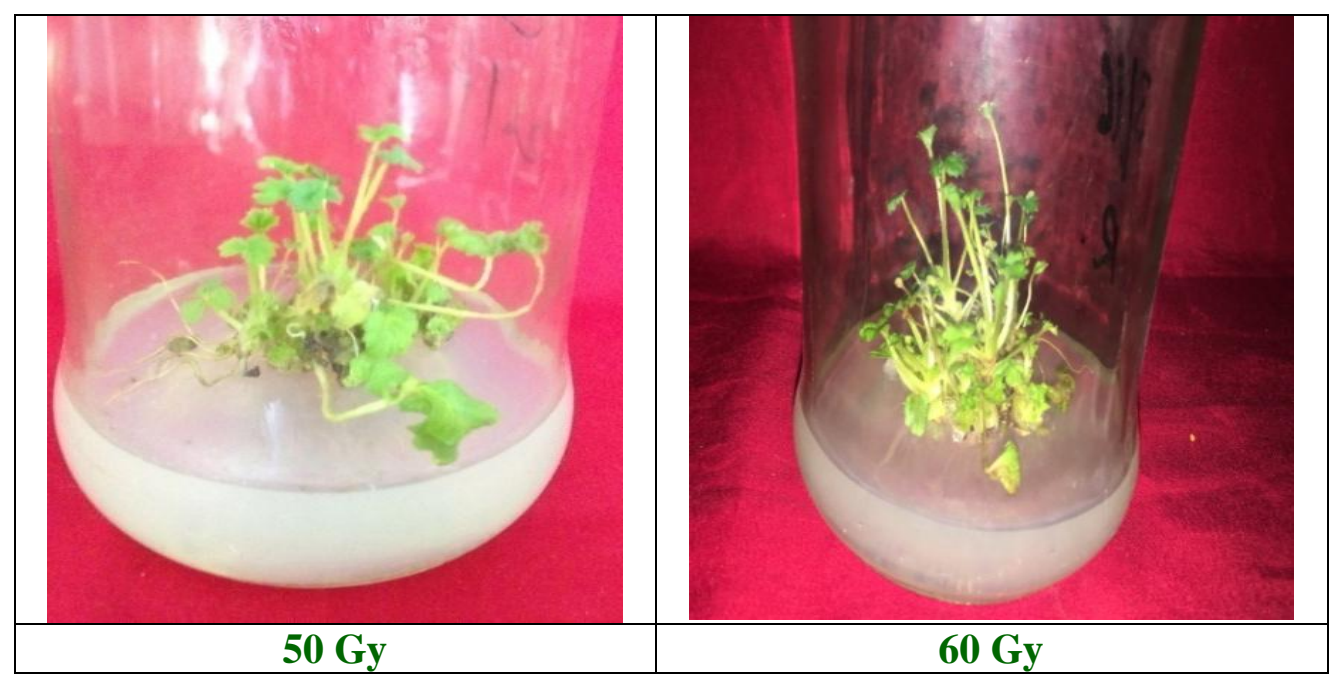

Fig.1 Effect of different doses of gamma irradiations on shoot parameters

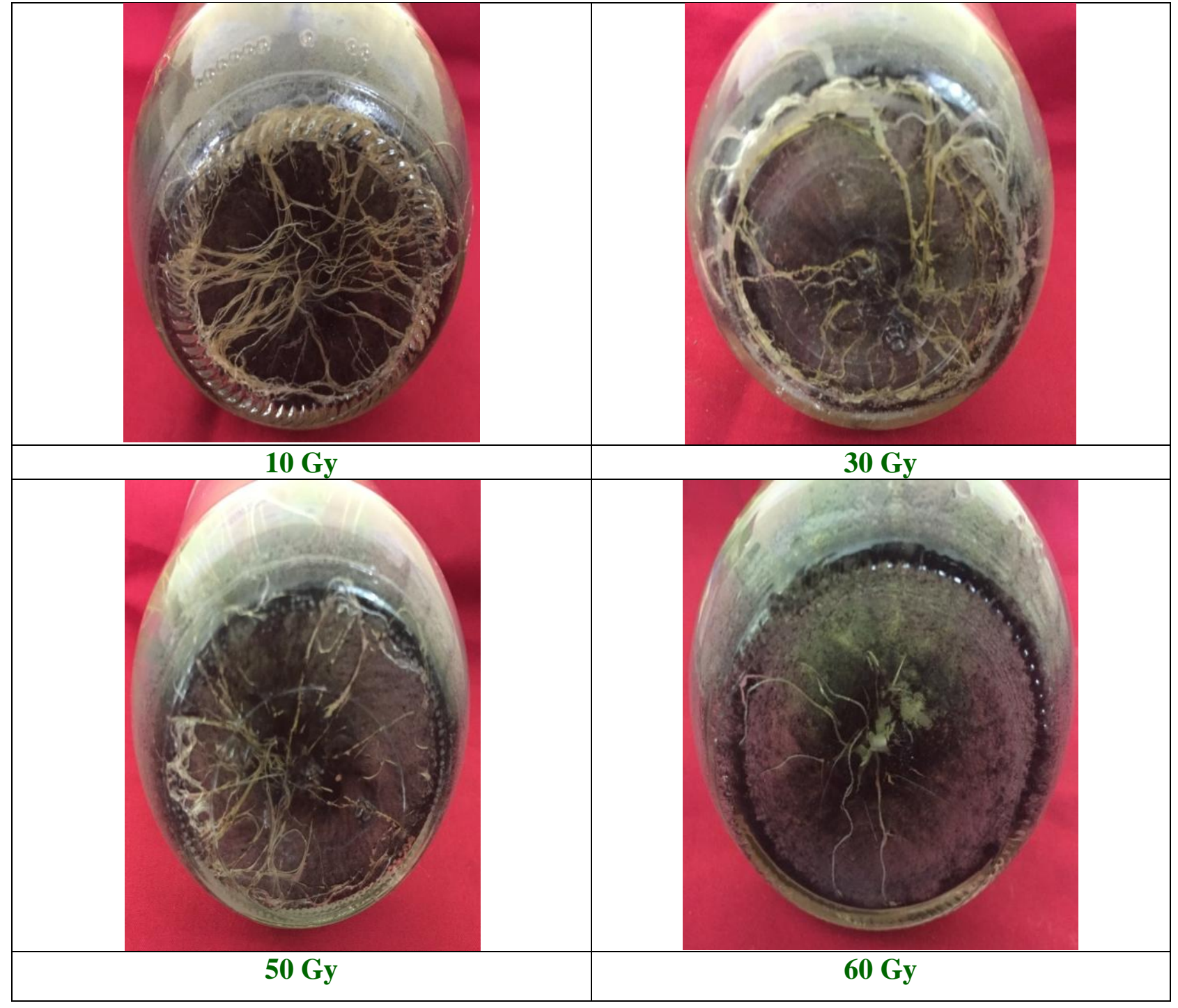


Fig.2 Effect of gamma rays on root characters of strawberry
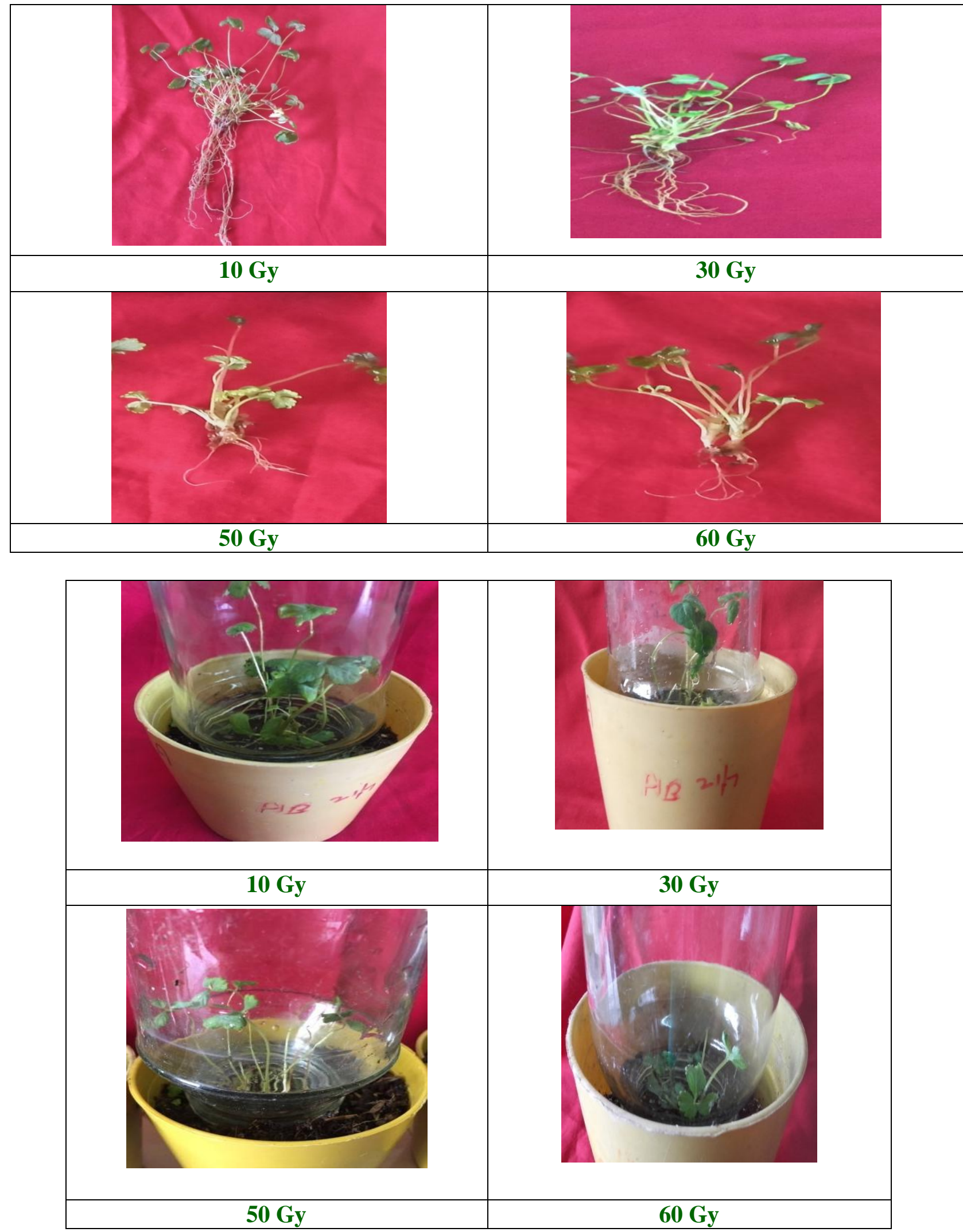
Fig.3 Hardening of rooted plantlets arising from different gamma rays doses

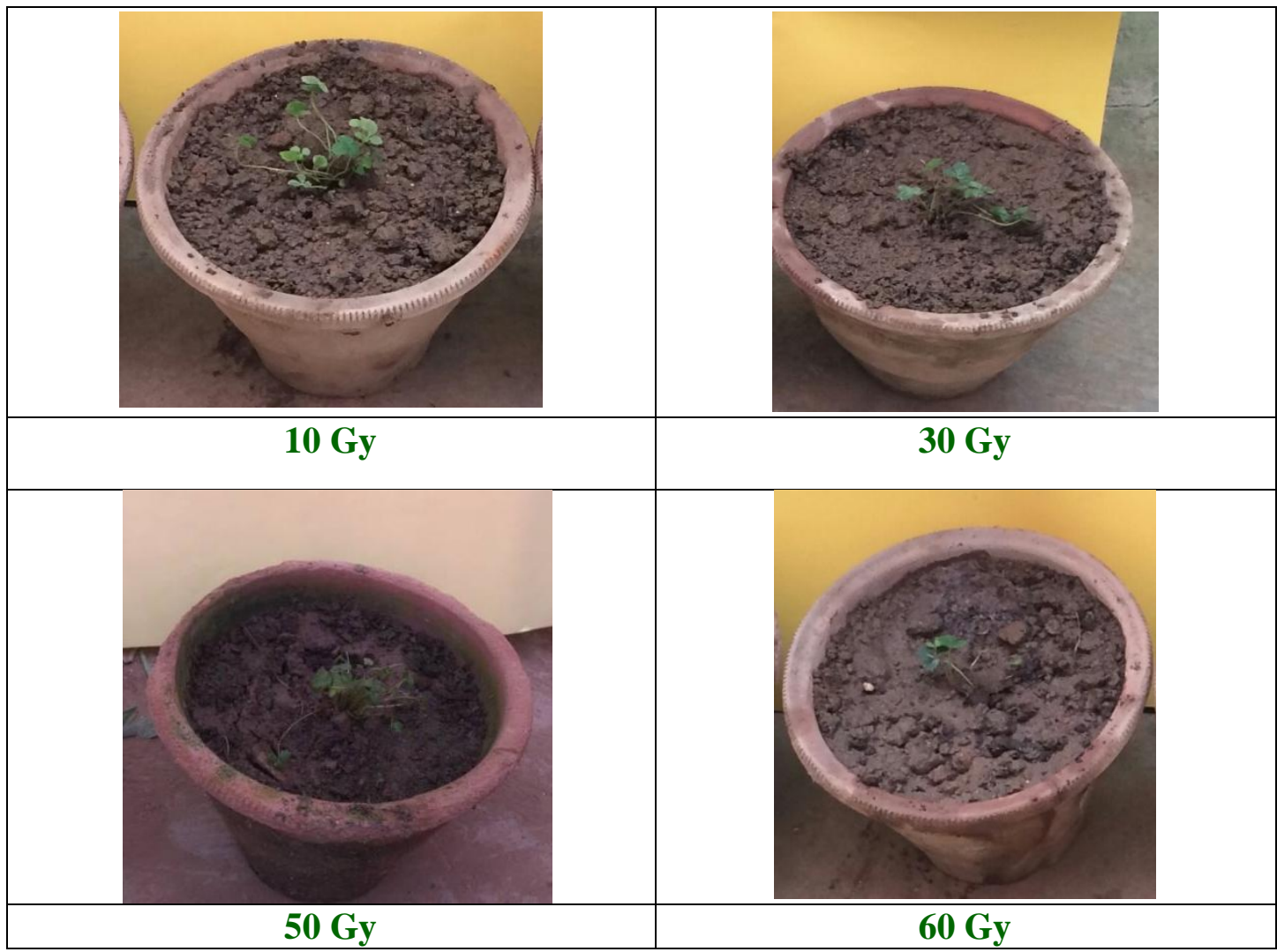

Maximum average number of roots (5.58) was observed in cultures irradiated with 10 Gy and the minimum average number of roots (1.84) was obtained in case of cultures irradiated with $60 \mathrm{~Gy}$. Regarding the root length, same results were observed as maximum root length $(3.62 \mathrm{~cm})$ was obtained in case of cultures irradiated with $10 \mathrm{~Gy}$. It has been observed that as the dosage of gamma rays increased the root parameters decreased. Jain (1997) reported the inhibitory effects of higher doses of gamma rays on strawberry cultures. He found that the number of roots per shoot decreased at higher gamma dosage (10 KR and $15 \mathrm{KR}$ ).

The data as presented in Table 4 revealed that the per cent survival of rooted plantlets was significantly lower in the irradiated plantlets than control. The highest per cent of survival $(86.66 \%)$ was obtained in plantlets which were not subjected to gamma irradiation followed by $10 \mathrm{~Gy}(75.55 \%)$. Whereas, the lowest survival per cent was obtained in the plantlets irradiated with 60 Gy $(46.44 \%)$. The response of the irradiation was found to be significantly different among different gamma irradiation doses. The results regarding the number of leaves after 7 weeks of hardening were depicted in Figure 3. Maximum number of leaves per plantlet differed significantly with the dosage of gamma rays (Table 4) the data mentioned here revealed that maximum number of leaves per plantlet (5.68) were observed in case of cultures irradiated with 10 Gy followed by $30 \mathrm{~Gy}$. It must be emphasised here that the young plants are very delicate when first taken out of the tubes and must be carefully handled (Mullin et al., 1974 and Murashige, 1977). Tiwari and Kumar (2011) observed higher percentage of survival at lower doses and poor survival at higher doses 
in all the generations of Calendula officinalis. Shukla et al., (1986) found the reduction survival of plants after exposure to gamma rays with the increase of dose in Rudbeckia laciniata.

Stimulatory effects of low doses of gamma rays on strawberry can be related to hypothesis that the low dose irradiation induce growth stimulation by changing the hormonal signalling network in plant cells or increase the anti-oxidative stress capacity of the cells to easily overcome the stress factors such as fluctuations of light intensity and temperatures in the growth condition (Wi et al., 2007). In contrast the high dose irradiation that caused growth inhibition has been ascribed to the cell cycle arrest at G2/ M phase during somatic cell division and /or various damages in the entire genome (Preussa and Britta, 2003).

From the results, it could be concluded that low doses of gamma radiation could simply be used for better survival and growth in strawberry under in vitro conditions.

\section{References}

Al-Oudat M. 1990. Effect of low dose gamma irradiation on onion yield. Annals of Biology 6: 61- 67

Antonov M Velichov P Tsonev T S and Angelov M. 1989. Effect of gamma and laser irradiation on maize seeds and plants. ESNA, $\mathrm{XX}^{\text {th }}$ Annual Meeting, Wageningen, the Netherlands pp-44.

Antonov M. 1985. Effect of gamma irradiation and storage duration of maize seeds on certain biochemical changes in the grain, Pasteniev. D. Nauki 19-24

Baek M H Kim J H Chung B Y Kim J S Lee I S. 2005. Alleviation of salt stress by low dose g-irradiation in rice. Biologia Plantarum, 49 (2), 273-276.

Cambecedes J Duron M Decourtye L and Jalouzot R. 1992. Methodology of In vitro irradiation from Lonicera species, mutant description and biochemical characterisation. Acta Horticulturae 320:119-126.

Fowler D B and MacQueen K F. 1972. Effect of lower doses of, radiation on yield and other agronomic characters of spring wheat. Radiation Botany 12:349-353.

Freidman, S. T. 1985. Pre-sowing radiation stimulation of crop seeds. ESNA Newsletter, pp.126-148. Warszawa

Ghiorghita, A G I Toth E T and Popescu T T 1985. The influence of physiological stage of seeds at the irradiation moment on the effects induced by small doses of gamma rays ${ }^{60} \mathrm{Co}$ in Triticum aestivum. Rev. Roum. Biol. Ser. Biol. Veg. 30: 151-158

Grossman H H and Craig R. 1982. The effect of gamma irradiation of seeds on germination and plant morphology of Pelargonium hortorum L.H. Bailey. Journal of American Society for Horticultural Sciences 107: 72-75

Gunckel J E Sparrow A H. 1961. Encycl. Plant Physiology. In: Ruhland, W. (Ed.), Ionizing Radiation: Biochemical, Physiological and Morphological Aspects of Their Effects on Plants. Springer-Verlag, Berlin, pp. 555.

Jain S M. 1997. Creation of variability by mutation and tissue culture for improving plants. Acta Horticulturae 447:69-77

Karim R Ahmed F Krishna U Roy Ara T Islam R and Hossain M. 2015. Varietal improvement of strawberry (Fragaria $\mathrm{x}$ ananassa Dutch.) through somaclonal variation using in vitro techniques. Journal of Agricultural Sciences and Technology 17: 977-986. 
Kim J H Baek M H Chung B Y Wi S G Kim J S. 2004. Alterations in the photosynthetic pigments and antioxidant machineries of red pepper (Capsicum anпиит L.) seedlings from gamma-irradiated seeds. Journal of Plant Biology 47: 314-321.

Kim J H Chung B Y Kim J S Wi S G. 2005. Effects of in Planta gamma-irradiation on growth, photosynthesis, and antioxidative capacity of red pepper (Capsicum annuum L.) plants. Journal of Plant Biology 48: 47-56

Kim J S Lee Y K Park H S Back M H Kim D H. 2000. Influence of low dose gamma radiation on the growth of maize (Zea mays L.) varieties Korean. Journal of Environment and Agriculture 19: 328331.

Lage L S C and Esquibel M A. 1997. Growth stimulation produced by methylene blue treatment in sweet potato. Plant Cell Tissue Organ Culture, 48: 77-81.

Laneri U franconi R and Altvista P. 1990. Somatic mutagenesis of Gerbers jamesonii Hybr. Irradiation and in vitro culture. Acta horticulturae 280:395402.

Mishra P J Ganapathi T R Suprasanna P and Bapa V A. 2007. Effect of Single and Recurrent Gamma Irradiation on in vitro Shoot Cultures of Banana. International Journal of Fruit Science 7(1):47-57.

Mullin R. H Smith S H Frazier N W Schlegel

D E and MacCall S R. 1974. Meristem culture frees strawberries of mild yellow edge, pallidosis and mottle diseases. Phytopathology 64: 14251429.

Murashige T. 1997. Plant cell and organ culture as horticultural practices. Acta Horticulturae, 78: 17-30.

Preussa S B and Britta A B. 2003. A DNA- damage- induced cell cycle checkpoint. Arabidopsis. Genetics, 164: 323- 334.

Radhadevi D S Nayar N K. 1996. Gamma rays induced fruit character variations in Nendran, a variety of banana (Musa paradasiaca L.). Geobios 23: 88-93.

Shukla R Nath P Jugran H M and Gupta M N. 1986. Studies on gamma radiation of Rudbeckia Laciniata cv. 'Golden Glow'. Journal of Nuclear Agriculture and Biology 15 (4):207-210.

Tiwari A K and Kumar V. 2011. Gamma ray induced morphological changes in pot marigold (Calendula officinalis). Progressive Agriculture, 11: 99-02

Wi S G Chung B Y and Kim J S. 2007. 'Effects of gamma irradiation on morphological changes and biological responses in plants'. Micron 38: 553- 564.

Wi, S.G., Chung, B.Y., Kim, J.H., Baek, M.H., Yang, D.H., Lee, J.W., Kim, J.S., 2005. Ultrastructural changes of cell organelles in Arabidopsis stem after gamma irradiation. J. Plant Biol. 48, 195-200.

\section{How to cite this article:}

Rucku Gupta, V.K. Wali, Parshant Bakshi, Guruupkar Singh, Rafiq Ahmad Shah and Sohnika Rani. 2018. Effects of Gamma Irradiation on Shoot, Root and Survival Percent in Strawberry cv. Chandler under In vitro Conditions. Int.J.Curr.Microbiol.App.Sci. 7(03): 1173-1182. doi: https://doi.org/10.20546/ijcmas.2018.703.139 